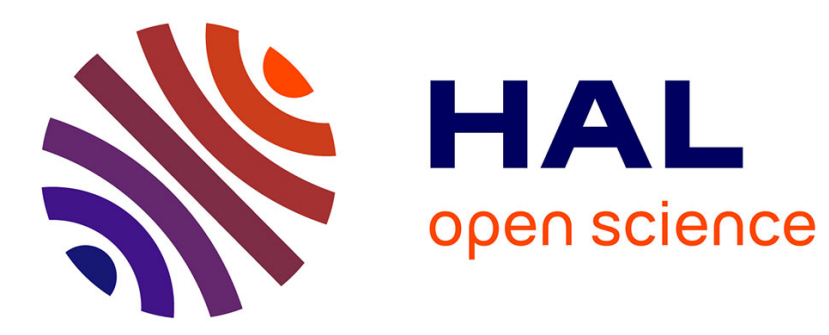

\title{
Magnetic and magnetocaloric properties of Gd2In0.8X0.2 compounds (X=Al, Ga, Sn, Pb)
}

Sophie Tencé, Bernard Chevalier

\section{To cite this version:}

Sophie Tencé, Bernard Chevalier. Magnetic and magnetocaloric properties of Gd2In0.8X0.2 compounds (X=Al, Ga, Sn, Pb). Journal of Magnetism and Magnetic Materials, 2016, 399, pp.46-50. 10.1016/j.jmmm.2015.09.058 . hal-01236177

\section{HAL Id: hal-01236177 \\ https://hal.science/hal-01236177}

Submitted on 13 Jan 2021

HAL is a multi-disciplinary open access archive for the deposit and dissemination of scientific research documents, whether they are published or not. The documents may come from teaching and research institutions in France or abroad, or from public or private research centers.
L'archive ouverte pluridisciplinaire HAL, est destinée au dépôt et à la diffusion de documents scientifiques de niveau recherche, publiés ou non, émanant des établissements d'enseignement et de recherche français ou étrangers, des laboratoires publics ou privés. 


\title{
Magnetic and magnetocaloric properties of $\mathrm{Gd}_{2} \mathrm{In}_{0.8} \mathrm{X}_{0.2}$ compounds $(\mathrm{X}=\mathrm{Al}, \mathrm{Ga}, \mathrm{Sn}, \mathrm{Pb})$
}

\author{
Sophie Tencé ${ }^{\mathrm{a}, \mathrm{b}, *}$, Bernard Chevalier ${ }^{\mathrm{a}, \mathrm{b}}$ \\ ${ }^{a}$ CNRS, ICMCB, UPR 9048, F-33600 Pessac, France \\ ${ }^{\mathrm{b}}$ Univ. Bordeaux, ICMCB, UPR 9048, F-33600 Pessac, France
}

Keywords:

Intermetallic synthesis

Metamagnetism

Ferromagnetism

Magnetocaloric properties

\begin{abstract}
A B S T R A C T
We show that it is possible to replace in $\mathrm{Gd}_{2}$ In some amount of In by $\mathrm{X}=\mathrm{Al}$, Ga, Sn and $\mathrm{Pb}$ to obtain $\mathrm{Gd}_{2} \mathrm{In}_{1}{ }_{x} \mathrm{X}_{x}$ samples after melting. The magnetic and magnetocaloric properties of the $\mathrm{Gd}_{2} \mathrm{In}_{0.8} \mathrm{X}_{0.2}$ in termetallic compounds have been investigated through $d c$ magnetization measurements. We evidence that the substitution of $\mathrm{Al}$ and Ga for In barely changes the Curie temperature $T_{\mathrm{C}}$ but decreases the second magnetic transition temperature $T^{\prime}$ which corresponds to the transition from a ferromagnetic to an antiferromagnetic state. On the other hand, the substitution of $\mathrm{Sn}$ and $\mathrm{Pb}$ for In strongly increases $T_{\mathrm{C}}$ and changes the nature or even suppresses the transition at lower temperature. This magnetic behavior gives rise to an interesting way to tune the Curie temperature near room temperature without diluting the Gd network and thus to modify the magnetocaloric effect in $\mathrm{Gd}_{2} \mathrm{In}_{1}{ }_{x} \mathrm{X}_{x}$ compounds.
\end{abstract}

\section{Introduction}

Gd based intermetallics have attracted much attention these last years for their magnetic and magnetocaloric properties. These studies were strongly motivated by the high magnetocaloric effect (MCE) of Gd or by the discovery of the giant MCE in $\mathrm{Gd}_{5} \mathrm{Ge}_{2} \mathrm{Si}_{2}[1]$. Among these intermetallics, $\mathrm{Gd}_{2}$ In is subjected to particular in terest because of its unusual magnetic properties. It crystallizes in the hexagonal type structure $\mathrm{Ni}_{2}$ In (space group $P 6_{3} / \mathrm{mmc}$ ) corre sponding to a filled NiAs structure with the lattice parameters $a=5.413$ and $c=6.756 \AA$ [2]. The Gd atoms occupy two sites in $2 a$ $\left(\begin{array}{lll}0 & 0 & 0\end{array}\right)$ and $2 d(1 / 32 / 33 / 4)$ and the In atoms one site $2 c(1 / 32 / 31 /$ $4)$. As most of the $\mathrm{R}_{2} \mathrm{In}\left(R=\right.$ rare earth) binaries, $\mathrm{Gd}_{2} \mathrm{In}$ exhibits a ferromagnetic (FM) ordering below room temperature, and in its case at $T_{\mathrm{C}}=190 \mathrm{~K}$ [3 7]. Besides, $\mathrm{Gd}_{2}$ In undergoes an anti ferromagnetic (AFM) transition at $T^{\prime}=100 \mathrm{~K}$ and presents a me tamagnetic behavior at low temperature. Indeed, the Néel tem perature is progressively supressed with increasing applied field. The nature of the antiferromagnetic and the ferromagnetic struc tures remains unclear due to the high absorption of neutrons by gadolinium which does not enable a precise determination of the magnetic structure by means of neutron diffraction. Notably, the magnetization value at low temperature is far from zero suggest ing the existence of a possible ferromagnetic component (canted or helical AFM structure). Likewise, the isothermal magnetization

\footnotetext{
* Corresponding author at: CNRS, ICMCB, UPR 9048, F-33600 Pessac, France.

E-mail address: tence@icmcb-bordeaux.cnrs.fr (S. Tencé).
}

curves between $T_{\mathrm{C}}$ and $T^{\prime}$ exhibit a linear behavior at low fields, different from that of a simple ferromagnet [6]. Another interest ing point concerning the magnetic properties of $\mathrm{Gd}_{2} \mathrm{In}$ is its be havior in the paramagnetic state, evidencing an effective moment significantly higher than that of the free $\mathrm{Gd}^{3+}$ ion $\left(7.94 \mu_{\mathrm{B}}\right)$, i.e. between 8.7 and $9.6 \mu_{\mathrm{B}}$ according to different studies [7,3,8]. It reveals the participation of the Gd $5 d$ electrons to the total mo ment via the polarization of these itinerant electrons and thus the key role of the $4 f 5 d$ exchange in the magnetic interactions and orders. This high effective magnetic moment, also evidenced by $\mathrm{M}(\mathrm{H})$ measurements, makes $\mathrm{Gd}_{2} \mathrm{In}$ an interesting compound for the MCE.

The unusual magnetic behavior of $\mathrm{Gd}_{2}$ In may be attributed to the competition between anisotropic exchange interactions. The study of the dilution of the Gd network with non magnetic Y or La atoms enabled to better understand this competition. The dilution of the rare earth network leads to a decrease of $T_{\mathrm{C}}$ as expected, but also to the progressive vanishing of $T^{\prime}$ until its total suppression at a critical composition around $x=0.5$ for $\mathrm{Gd}_{2} \quad$ ( $(\mathrm{La}, \mathrm{Y})_{x} \mathrm{In}[8 \mathrm{10}$ ]. It exists two ranges of correlation lengths $R_{\mathrm{c}}$ between $\mathrm{Gd}$ atoms, namely the range of $3.3 \AA<R_{\mathrm{C}}<3.6 \AA$ between Gd1 Gd1 and $\mathrm{Gd} 1 \mathrm{Gd} 2$, and that of $R_{\mathrm{c}}>4 \AA$ between Gd2 Gd2, with $R_{\mathrm{c}}=\mathrm{k}_{\mathrm{F}} \mid \mathbf{R}_{\mathbf{i}}$ $\mathbf{R}_{\mathbf{j}} \mid$, K $K_{F}$ being the Fermi vector and $\left|\mathbf{R}_{\mathbf{i}} \quad \mathbf{R}_{\mathbf{j}}\right|$ the distance between the atoms $\mathrm{i}$ and $\mathrm{j}$. This implies the occurrence of two exchange inter actions of different sign and strength. The difference between these two types of exchange coupling could be the main cause of the competition between the FM and the AFM state.

In this work we present the results of the substitution of the non magnetic In specie by isoelectronic p elements as Al and Ga 
and element with one more p electron as $\mathrm{Sn}$ and $\mathrm{Pb}$. The objective was to modify the magnetic and magnetocaloric properties of $\mathrm{Gd}_{2}$ In without diluting the Gd network, in particular to increase the Curie temperature. Composition and homogeneity are checked by $\mathrm{X}$ ray diffraction (XRD) and microprobe analysis. Magnetization measurements are presented to evidence the influence of the substitution of In by another p element. All results are discussed in comparison to those of $\mathrm{Gd}_{2}$ In and diluted compounds $\mathrm{Gd}_{2} \quad{ }_{x}(\mathrm{La}, \mathrm{Y})$ ${ }_{x}$ In.

\section{Experiments}

Samples with the following nominal compositions $\mathrm{Gd}_{2} \mathrm{In}_{0.8} \mathrm{X}_{0.2}$ for $\mathrm{X}=\mathrm{Al}, \mathrm{Ga}, \mathrm{Sn}$ and $\mathrm{Pb}$ were prepared by melting precisely weighted amounts of high purity elements Gd, In and X (99.9\%) in an arc melting furnace. Melting was performed three times to ensure a good homogeneity under a purified argon gas atmo sphere. The weight losses during the overall melting process were less than $0.8 \mathrm{wt} \%$ and finally the as cast samples were quenched by switching off the power supply.

The composition and the homogeneity of the samples were checked by microprobe analysis using a Cameca SX 100 instru ment. The analysis was performed on the basis of intensity mea surements of $G d L \alpha_{1}$, In $L \alpha_{1}, A l K \alpha_{1}, G a L \alpha_{1}, S n L \alpha_{1}$ and $P b M \alpha_{1}$ $\mathrm{X}$ rays emission lines.

Routine $\mathrm{X}$ ray powder diffraction was performed with the use of a Philips 1050 diffractometer ( $\mathrm{Cu} \mathrm{K} \mathrm{K}_{\alpha}$ radiation) for the char acterization of the structural type and for the phase identification. As the samples are sensitive to air, they were ground to produce powder in a glove box and $\mathrm{X}$ ray diffraction measurements were performed under a protected atmosphere.

Magnetization measurements were performed using a super conducting quantum interference device (SQUID) magnetometer (Quantum Design MPMS XL) in the temperature range $5360 \mathrm{~K}$ and in fields up to $4.6 \mathrm{~T}$.

\section{Microprobe analysis and X-ray diffraction}

The energy dispersive $\mathrm{X}$ ray (EDX) profiles are shown on Fig. 1 .

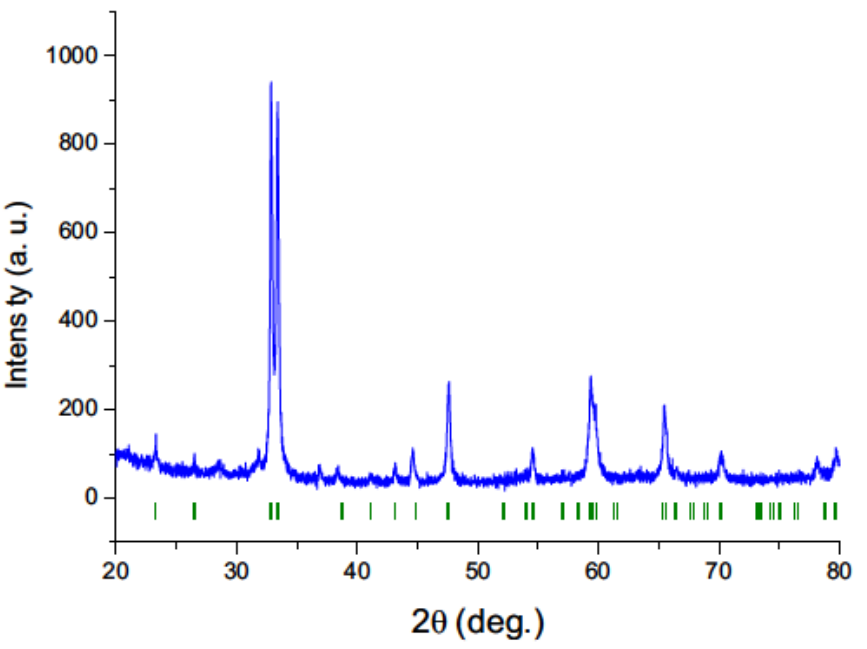

Fig. 2. X-ray diffraction pattern of $\mathrm{Gd}_{2} \mathrm{In}_{0.8} \mathrm{Al}_{02}$. The ticks correspond to the peak positions of the phase with the space group $P 6_{3} / \mathrm{mmc}$.

The EDX analysis reveals a relatively good homogeneity of com position along the samples and confirms that the $\mathrm{p}$ metal $\mathrm{X}$ is found indeed inside the pseudo binary phases $\mathrm{Gd}_{2} \mathrm{In}_{0.8} \mathrm{X}_{02}$ with an amount of $\mathrm{X}$ close to the expected value of $6.6 \%$ as atomic com position percentage. The content of $\mathrm{Pb}$ is slightly smaller than the nominal one either because of the much larger size of $\mathrm{Pb}$ with respect to In and less solubility or most likely due to $\mathrm{Pb}$ losses during melting.

All $\mathrm{X}$ ray diffractograms present the same reflections as those of $\mathrm{Gd}_{2}$ In $[2,4,5]$, confirming that the samples crystallize in the $\mathrm{Ni}_{2}$ In type structure with the $\mathrm{P}_{3} / m m c$ space group (Fig. 2). The small extra peaks come from oxide impurities, the samples being very sensitive to oxygen, and sample holder in Al. The lattice parameters of $\mathrm{Gd}_{2} \mathrm{In}_{0.8} \mathrm{X}_{0.2}$ compounds are gathered in Table 1 . For $\mathrm{X}=\mathrm{Al}$ and $\mathrm{Ga}$ the lattice parameters are close to $a=5.39$ and $c=6.74 \AA$, i.e. significantly smaller than those of $\mathrm{Gd}_{2}$ In $(a=5.413$ and $c=6.756 \AA$ [4]) in agreement with the smaller metallic radius of $\mathrm{Al}(r=1.43 \AA)$ and $\mathrm{Ga}(r=1.41 \AA)$ with respect with In $(r=1.66 \AA)$ [11]. In the case of $X=\mathrm{Sn}$ and $\mathrm{Pb}, a$ is higher and $c$ slightly smaller than for the pure binary $\mathrm{Gd}_{2} \mathrm{In}$, resulting eventually in a higher
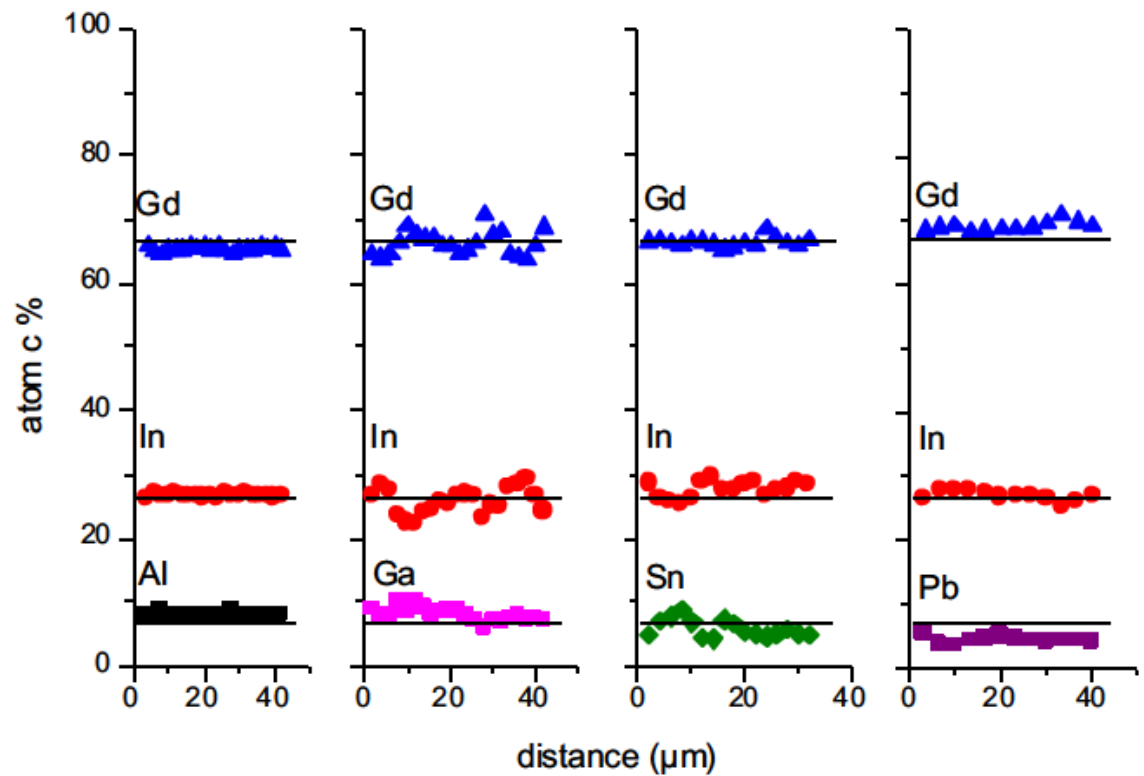

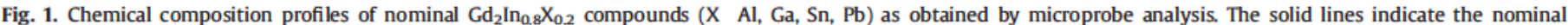
composition. 
Table 1

Lattice parameters of $\mathrm{Gd}_{2} \mathrm{In}_{1}{ }_{x} \mathrm{X}_{x}$ compounds determined from X-ray diffraction.

\begin{tabular}{llllll}
\hline Compound & $\mathrm{Gd}_{2} \mathrm{In}$ & $\mathrm{Gd}_{2} \mathrm{In}_{0.8} \mathrm{Al}_{0.2}$ & $\mathrm{Gd}_{2} \mathrm{In}_{0.8} \mathrm{Ga}_{0.2}$ & $\mathrm{Gd}_{2} \mathrm{In}_{0.8} \mathrm{Sn}_{0.2}$ & $\mathrm{Gd}_{2} \mathrm{In}_{0.8} \mathrm{~Pb}_{0.2}$ \\
\hline$a(\AA)$ & 5.413 & $5.391(1)$ & $5.393(1)$ & $5.430(1)$ & $5.435(1)$ \\
$c(\AA)$ & 6.756 & $6.742(1)$ & $6.748(1)$ & $6.744(1)$ & $6.751(1)$ \\
$V\left(\AA^{3}\right)$ & 171.4 & 169.7 & 170.0 & 172.2 & 172.7 \\
$T_{\mathrm{C}}(\mathrm{K})$ & 188 & 190 & 190 & 255 & 243 \\
$T^{\prime}(\mathrm{K})$ & 104 & 68 & 82 & - & 40 \\
\hline
\end{tabular}

volume cell. This is in agreement for example with the evolution of the lattice parameter $a$ in the cubic solid solution $\mathrm{Gd}\left(\operatorname{In}_{1}{ }_{x} \mathrm{Sn}_{x}\right)_{3}$ since $a$ increases linearly from $4.611 \AA$ for $\mathrm{GdIn}_{3}$ to $4.681 \AA$ for $\mathrm{GdSn}_{3}[12]$. Likewise, it is coherent with $\mathrm{GdPb}_{3}$ which has a higher cell parameter ( $a=4.816 \AA$ ) than its homologous $\operatorname{GdIn}_{3}$ [13]. More generally, by substituting $\mathrm{X}$ for In, we observe that the $a$ parameter is more affected than the $c$ one. This can be understood regarding the smallest Gd In distance ( $3.124 \AA$ ) which is proportional to $a$ only, whereas the next smallest Gd In distance ( $3.375 \AA$ ) is pro portional to $c$.

\section{Magnetic properties}

The temperature dependence of the magnetization of the $\mathrm{Gd}_{2} \mathrm{In}_{0.8} \mathrm{X}_{0.2}$ samples is displayed in Figs. 3 and 4. As evidenced on Fig. 3 the features of the magnetization curve of $\mathrm{Gd}_{2}$ In are kept trough In substitution by $\mathrm{Al}$ or $\mathrm{Ga}$. In particular, upon decreasing temperature, we still observe a strong increase of the magnetiza tion around $T_{\mathrm{C}}=190 \mathrm{~K}$ and a sharp drop at a lower temperature $T^{\prime}$. These two anomalies correspond to a FM transition and an AFM one, respectively. It is noteworthy that for an isoelectronic element of In, $T_{\mathrm{C}}$ barely changes whereas $T$ decreases significantly since $T^{\prime}=82 \mathrm{~K}$ for $\mathrm{X}=\mathrm{Ga}$ and $T^{\prime}=68 \mathrm{~K}$ for $\mathrm{X}=\mathrm{Al}$. Based on resistivity and magnetic measurements, it was postulated that the magnetic ground state of $\mathrm{Gd}_{2}$ In was most likely not a conventional anti ferromagnetic one and could correspond to a spiral AFM structure along the $c$ axis with a possible tilt of the moments toward the $c$ axis [4]. As the magnetization value at low temperatures is sig nificantly weaker for $\mathrm{X}=\mathrm{Ga}, \mathrm{Al}$ than for $\mathrm{In}$, it may indicate that the ferromagnetic component is smaller for these pseudo binaries.

The variation of the transition temperatures of $\mathrm{Gd}_{2} \mathrm{In}$ with ap plied pressure P was studied by Liu et al. [14]. In particular, they showed that $T^{\prime}$ decreases with increasing pressure in the same

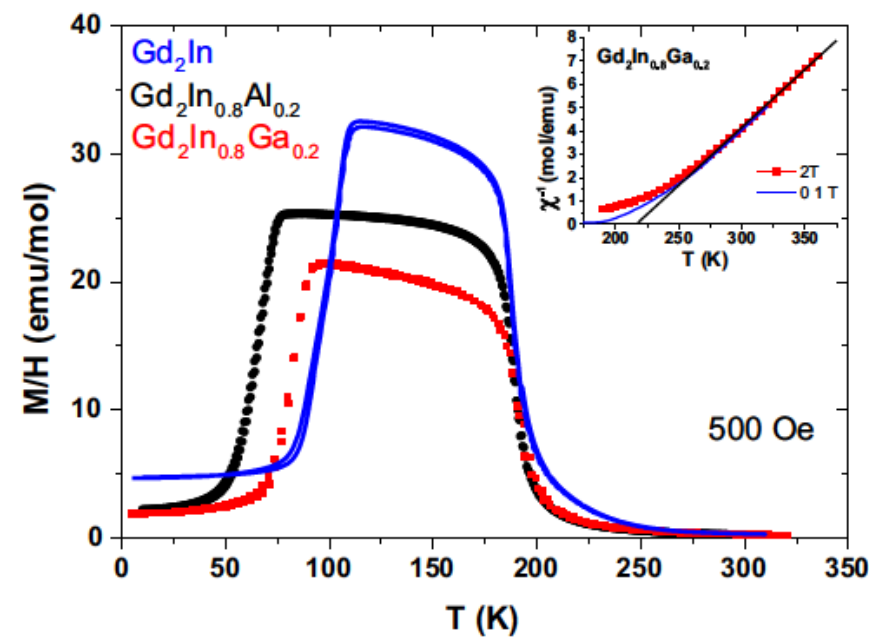

Fig. 3. Temperature dependence of the magnetization of $\mathrm{Gd}_{2} \mathrm{In}_{0.8} \mathrm{X}_{0.2}$ for $\mathrm{X}$ In, $\mathrm{Al}$, Ga after zero-field cooling and field cooling. The inset shows the inverse of the susceptibility of $\mathrm{Gd}_{2} \mathrm{In}_{0.8} \mathrm{Ga}_{0.2}$ measured at 2 and $0.1 \mathrm{~T}$.

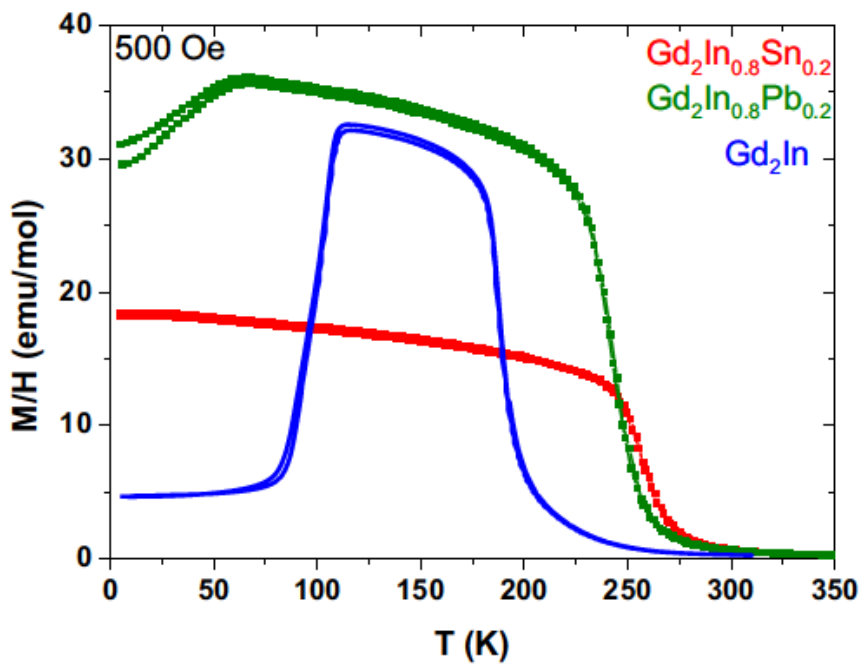

Fig. 4. Temperature dependence of the magnetization of $\mathrm{Gd}_{2} \mathrm{In}_{0.8} \mathrm{X}_{0.2}$ for $\mathrm{X} I \mathrm{In}, \mathrm{Sn}$, $\mathrm{Pb}$ after zero-field cooling and field cooling.

way as does the Curie temperature of weak itinerant $3 \mathrm{~d}$ ferro magnetic materials, suggesting the important role of conduction electrons in the magnetic ordering [15]. Interestingly, in the se quence In $\mathrm{Ga} \mathrm{Al}$ we observe the same order of magnitude of di minution of $T^{\prime}$ with decreasing unit cell volume (Table 1), con sidering that a decrease of $1 \%$ of the volume corresponds usually to an applied pressure of typically $1 \mathrm{GPa}$. Therefore, with the sub stitution of $\mathrm{Ga}$ and $\mathrm{Al}$ for In, the chemical pressure has a similar effect as a physical pressure applied on $\mathrm{Gd}_{2} \mathrm{In}$. The variation of the Curie temperature with chemical pressure is less pronounced than with applied pressure because, for these isoelectronic compounds, it depends mainly on the smallest Gd Gd distance equal to $c / 2$ which is barely affected by the p metal substitution. The physical pressure $\mathrm{P}$ has a more isotropic effect on the lattice parameters and interatomic distances and thus $T_{\mathrm{C}}$ increases more significantly with increasing $P$.

The magnetic properties were also measured at high tem peratures. As shown for example for $X=G a$, the inverse of the susceptibility in the paramagnetic state follows a Curie Weiss behavior in the investigated temperature range (inset of Fig. 3). The paramagnetic Curie Weiss temperature is equal to $217 \mathrm{~K}$ which is comparable to the values found by Gamari Seale et al. ( $\theta_{p}$ $=212 \mathrm{~K}[3])$ and Ilyn et al. $\left(\theta_{p}=230 \mathrm{~K}\right.$ [7]) for $\mathrm{Gd}_{2} \mathrm{In}$. The effective moment for $\mathrm{Gd}_{2} \mathrm{In}_{0.8} \mathrm{Ga}_{0.2}$ is $8.9 \mu_{\mathrm{B}} / \mathrm{Gd}$, i.e. much larger than the theoretical value predicted for a free trivalent Gd ion $\left(7.94 \mu_{\mathrm{B}}\right)$ as previously observed for $\mathrm{Gd}_{2}$ In $\left(9.6 \mu_{\mathrm{B}} / \mathrm{Gd}\right.$ [3], $9.09 \mu_{\mathrm{B}} / \mathrm{Gd}$ [7]). This large excess of moment was also observed in pure Gd and in many Gd compounds diluted with non magnetic metals. It is assigned to the spin polarization of the $5 d(G d)$ conduction electrons. Thus the $5 \mathrm{~d} 4 \mathrm{f}$ interactions are believed to play an important role in the magnetic order as well as in the field induced metamagnetic transition. This is supported for $\mathrm{Gd}_{2}$ In by band structure calcula tions using different methods $[16,17]$ which show that the density of state near the Fermi level is mainly due to the presence of Gd $5 d$ states which forms a narrow band. Notably, Singh et al. have clearly highlighted the role of the Gd $5 \mathrm{~d}$ moments in the meta magnetic behavior of $\mathrm{Gd}_{2} \mathrm{In}$.

Concerning $\mathrm{X}=\mathrm{Sn}$ and $\mathrm{Pb}$, the magnetic behavior differs more significantly with the substitution than for Al and Ga (Fig. 4). Both compounds exhibit a ferromagnetic transition but at higher tem perature than $\mathrm{Gd}_{2}$ In since $T_{\mathrm{C}}=255 \mathrm{~K}$ for $\mathrm{X}=\mathrm{Sn}$ and $T_{\mathrm{C}}=243 \mathrm{~K}$ for $\mathrm{X}=\mathrm{Pb}$. It is noticeable that the small modification of the non magnetic network yields a stronger variation of $T_{\mathrm{C}}$ than the dilu tion of the magnetic Gd network [9], emphasizing the importance 
of the electronic effect in this substitution. The Curie temperature depends on the magnetic moment and the exchange coupling which is function of the density of states at the Fermi level as well as the distance between rare earth atoms (RKKY interactions). As we may assume that Gd Gd distances and magnetic moments barely vary through In substitution, the evolution of $T_{C}$ is likely due to the modification of the DOS structure near the Fermi level. This would explain the modification of $T_{C}$ when replacing In by a non isoelectronic element whereas $T_{\mathrm{C}}$ stays almost constant for the isoelectronic metals Al and Ga. Further DFT (Density Func tional Theory) calculations need to be done to confirm this as sumption and to understand the role of the dopant atom in the change of the electronic structure.

The most striking change is observed for the AFM transition since its temperature is considerably reduced for $X=\mathrm{Pb}$ and even suppressed for $X=S n$ (see Fig. 4). In others words, the In sub stitution by elements with one more $p$ electron induces an in crease of the Curie temperature and a decrease or even a vanishing of $T^{\prime}$. Also, it is clear that the low temperature state of $\mathrm{Gd}_{2} \mathrm{In}_{0.8} \mathrm{~Pb}_{0.2}$ is not purely AFM which strongly support the establishment of a conical magnetic structure. The low temperature magnetic beha vior is very similar to those of the isotypes $R_{2} \operatorname{In}(R=\mathrm{Tb}, \mathrm{Er})$ [18] and diluted $\mathrm{Gd}_{2}{ }_{x}(\mathrm{La}, \mathrm{Y})_{x} \mathrm{In}[9,8]$ compounds. These results con firm the strong competition between the exchange interactions and the proximity of an instability between a FM and an AFM ground state.

The field dependence of the magnetization were further in vestigated and are depicted in Figs. 5 and 6 for $\mathrm{X}=\mathrm{Al}$, Ga and $\mathrm{X}=\mathrm{Sn}, \mathrm{Pb}$, respectively. For $\mathrm{X}=\mathrm{Al}$ and $\mathrm{Ga}$, we observe below $T^{\prime}$ a linear increase of the magnetization at low fields followed by a metamagnetic transition and eventually a tendency to saturate at high fields. This metamagnetic behavior is comparable to that of $\mathrm{Gd}_{2} \mathrm{In}$, as expected considering their similar $\mathrm{M}(\mathrm{T})$ behavior. Above
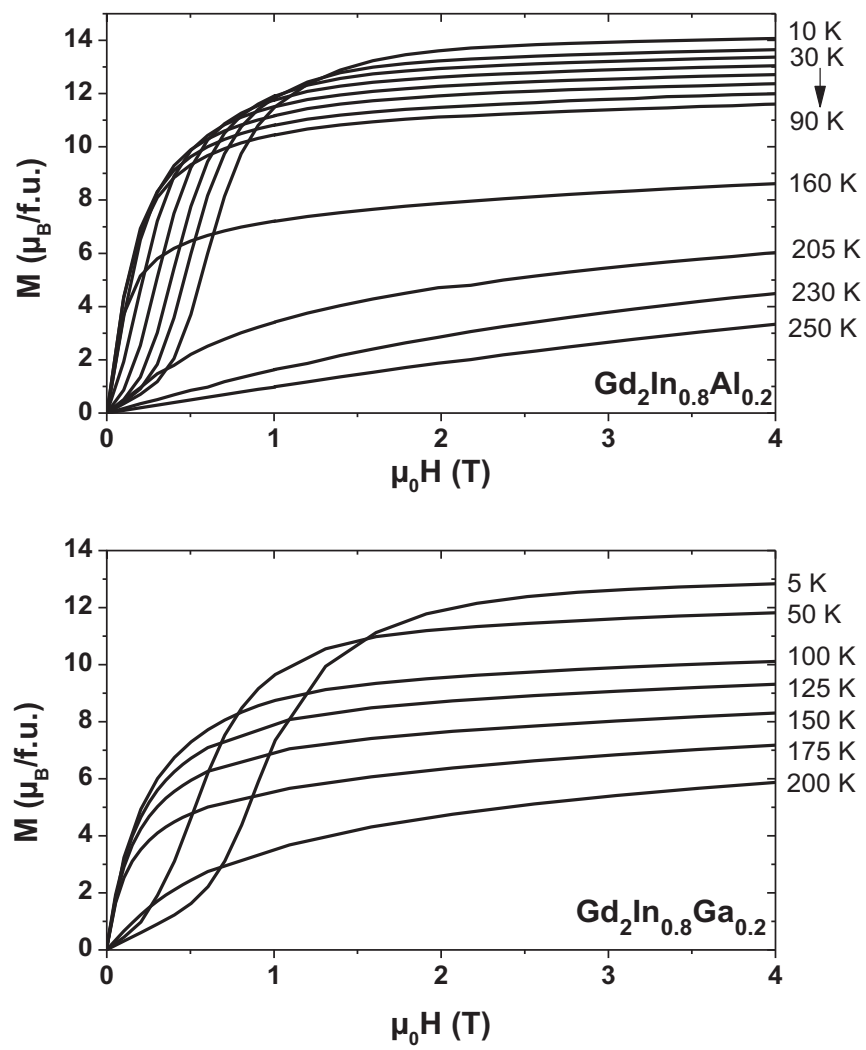

Fig. 5. Field dependence of the magnetization of $\mathrm{Gd}_{2} \mathrm{In}_{0.8} \mathrm{Al}_{0.2}$ and $\mathrm{Gd}_{2} \mathrm{In}_{0.8} \mathrm{Ga}_{0.2}$ at various temperatures.
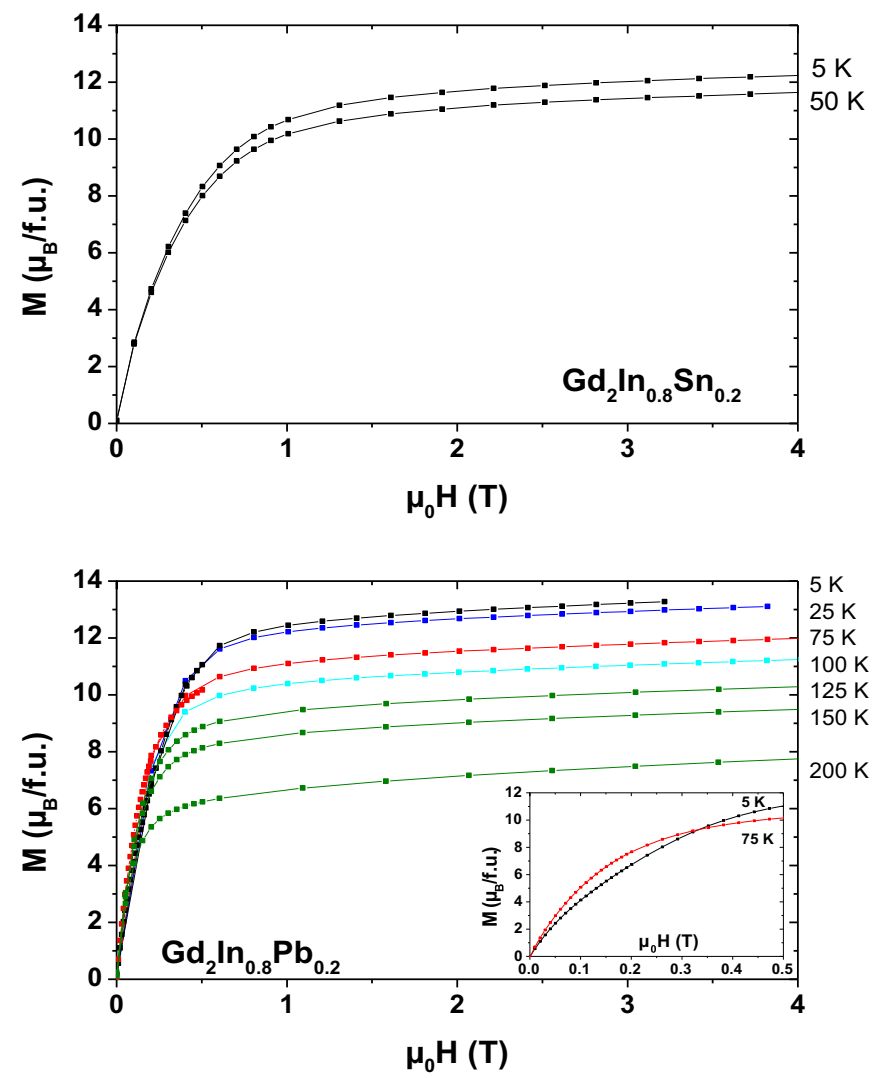

Fig. 6. Field dependence of the magnetization of $\mathrm{Gd}_{2} \mathrm{In}_{0.8} \mathrm{Sn}_{0.2}$ and $\mathrm{Gd}_{2} \mathrm{In}_{0.8} \mathrm{~Pb}_{0.2}$ at various temperatures. The inset in the lower figure shows the low field part of the isothermal magnetization curves at 5 and $75 \mathrm{~K}$ for $\mathrm{Gd}_{2} \mathrm{In}_{0.8} \mathrm{~Pb}_{0.2}$.

$T^{\prime}$, both compounds display a ferro like behavior with a negative curvature over the whole field range, in agreement with the $\mathrm{M}(\mathrm{T})$ measurements. At low temperature, the critical field $\mathrm{H}_{\mathrm{c}}$, de termined at the inflection point of the $\mathrm{M}(\mathrm{H})$, is found to be at 6 kOe and 9 kOe for $\mathrm{X}=\mathrm{Al}$ and Ga, respectively. As $\mathrm{H}_{\mathrm{c}}$ was mea sured around $12 \mathrm{kOe}$ for $\mathrm{Gd}_{2} \mathrm{In}$, the evolution of the critical field is coherent with the decrease of the temperature of the transition from $\mathrm{F}$ to $\mathrm{AM}$ order. For $\mathrm{Gd}_{2} \mathrm{In}_{0.8} \mathrm{Sn}_{0.2}$ the $\mathrm{M}(\mathrm{H})$ curves are very similar at $5 \mathrm{~K}$ and $50 \mathrm{~K}$ confirming that this pseudo binary exhibits the same magnetic order over the whole temperature range below $T_{C}$ (Fig. 6). The feature of the curves is compatible with a simple ferromagnetic or an helical ferromagnetic state. On the other hand the magnetic behavior of $\mathrm{Gd}_{2} \mathrm{In}_{0.8} \mathrm{~Pb}_{0.2}$ is somehow different. The $\mathrm{M}(\mathrm{H})$ feature at low fields and low temperatures is rather linear compared to that at temperature above $T^{\prime}$. In particular it is no ticeable that the magnetization value at low fields is higher at $75 \mathrm{~K}$ than at 5 or $25 \mathrm{~K}$ and both curves cross each other around $3 \mathrm{kOe}$ (see inset of Fig. 6). This results agrees well with the $M(T)$ curve and may suggest the presence of an helical FM structure at low temperatures and a FM structure above $T^{\prime}$.

\section{Magnetocaloric properties}

Magnetocaloric effect (MCE) was investigated for two selected compounds, namely $\mathrm{Gd}_{2} \mathrm{In}_{0.8} \mathrm{Al}_{0.2}$ and $\mathrm{Gd}_{2} \mathrm{In}_{0.8} \mathrm{~Pb}_{0.2}$. The iso thermal magnetic entropy change $\Delta S_{\mathrm{m}}$ was calculated by means of isothermal magnetization data and the use of the Maxwell rela tion. The temperature dependence of $\Delta S_{\mathrm{m}}(T)$ are plotted in Fig. 7 for magnetic fields variations between 1 and $4 \mathrm{~T}$. The MCE of both compounds displays a negative minimum in the vicinity of their Curie temperature as expected for a ferromagnetic phase 


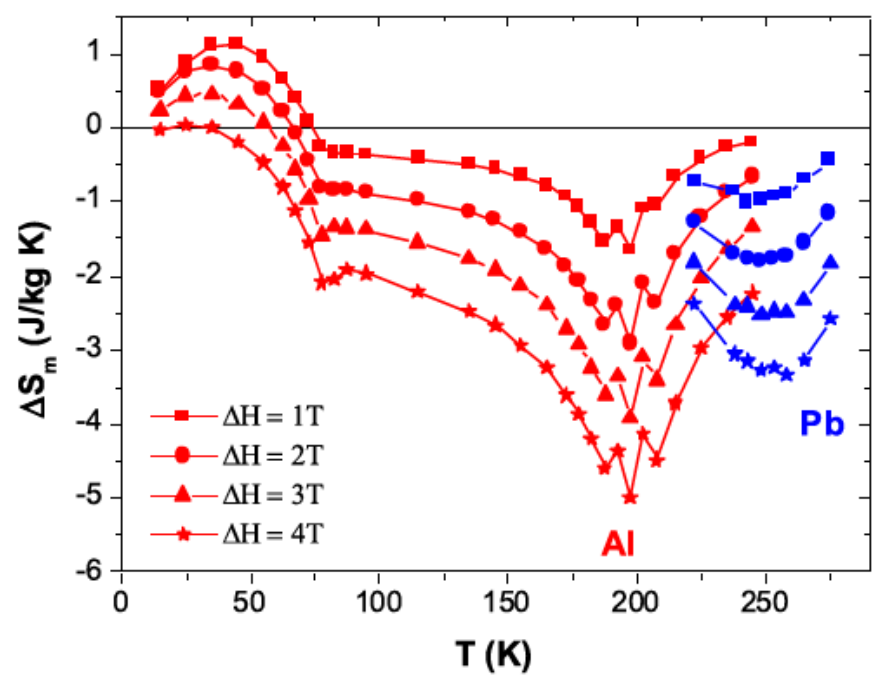

Fig. 7. Temperature dependence of the isothermal magnetic entropy change for $\mathrm{Gd}_{2} \mathrm{In}_{0.8} \mathrm{Al}_{0.2}$ and $\mathrm{Gd}_{2} \mathrm{In}_{0.8} \mathrm{~Pb}_{0.2}$ in red and blue symbols, respectively.

transition. These values reach $5.0 \mathrm{~J} \mathrm{~K}^{1} \mathrm{~kg}^{1}$ and $3.3 \mathrm{~J} \mathrm{~K}{ }^{1} \mathrm{~kg}{ }^{1}$ for $\mathrm{X}=\mathrm{Al}$ and $\mathrm{X}=\mathrm{Pb}$ respectively, for an applied field of $4 \mathrm{~T}$. The value is smaller for $\mathrm{X}=\mathrm{Pb}$ because of a higher $T_{\mathrm{C}}$ but also likely due to less homogeneity of the sample inducing a widening of the maximum of $\Delta S_{\mathrm{m}}$. However, the maximum of entropy change found for $\mathrm{X}=\mathrm{Al}$ is close to that of $\mathrm{Gd}_{2}$ In having the same $T_{\mathrm{C}}$, i.e. $4.5 \mathrm{~J} \mathrm{~K}^{1} \mathrm{~kg}{ }^{1}$ or $3.7 \mathrm{~J} \mathrm{~K}{ }^{1} \mathrm{~kg}{ }^{1}$ according to Bhattacharyya et al. [19] or Ilyn et al. [7] for an applied field of $4 \mathrm{~T}$.

The magnetocaloric effect of $\mathrm{Gd}_{2} \mathrm{In}_{0.8} \mathrm{Al}_{0.2}$ was measured down to low temperatures (see Fig. 7). As expected a second anomaly is observed near $T^{\prime}$ with a sharp decrease of $\left|\Delta S_{\mathrm{m}}(T)\right|$ with decreasing temperature. Beside, the sign of $\Delta S_{\mathrm{m}}(T)$ changes below $T$ in par ticular for the low applied magnetic fields. This inverse MCE is consistent with the occurrence of the antiferromagnetic state and is just more pronounced that the metamagnetic state is preserved when applying the field. A similar behavior was observed for $\mathrm{Gd}_{2}$ In with the presence of a maximum of the positive $\Delta S_{\mathrm{m}}(T)$ below $T$.

\section{Conclusion}

The substitution of In by some non magnetic elements in the binary $\mathrm{Gd}_{2}$ In has been investigated in order to modify its mag netocaloric effect in a quest of finding suitable refrigerant mate rials for magnetic cooling applications. In this way, we succeed to prepare $\mathrm{Gd}_{2} \mathrm{In}_{0.8} \mathrm{X}_{0.2}$ samples for $\mathrm{X}=\mathrm{Al}, \mathrm{Ga}, \mathrm{Sn}$ and $\mathrm{Pb}$ by melting the constituent elements. We showed that the substitution of isoelectronic elements as $\mathrm{Al}$ and $\mathrm{Ga}$ for In does not change the Curie temperature whereas the second transition at $T^{\prime}$ decreases significantly as observed for $\mathrm{Gd}_{2}$ In under increasing pressure. On the contrary, the substitution of non isoelectronic elements as Sn and $\mathrm{Pb}$ for In induces an increases of the Curie temperature in parallel to a strong diminution or even a vanishing of the transi tion at $T^{\prime}$. These substitutions clearly evidence the strong compe tition between the ferromagnetic and the antiferromagnetic in teractions since the ground state can be easily modified from one to the other magnetic state only by a small change in composition of the non magnetic element. DFT calculations would be helpful to compare the electronic density of states near the Fermi level be tween those compounds to better understand the role of the conduction electrons and dopant elements in the evolution of the magnetic properties with composition.

\section{Acknowledgments}

This work was supported by the ANR (Agence Nationale pour la Recherche) through the research project "MAGCOOL" (ANR 2010 STKE 008).

\section{References}

[1] V.K. Pecharsky, K.A. Gschneidner, Phys. Rev. Lett. 78 (1997) 4494.

[2] A. Palenzona, J. Less-Common Met. 16 (1968) 379-384.

[3] H. Gamari-Seale, T. Anagnostopoulos, J.K. Yakinthos, J. Appl. Phys. 50 (1979) 434-437.

[4] S.P. McAlister, J. Phys. F: Met. Phys. 14 (1984) 2167-2175.

[5] W. Bazela, A.J. Szytula, Less-Common Met. 138 (1988) 123-129.

[6] C.-S. Jee, C.L. Lin, T. Mihalisin, X.-Q. Wang, J. Appl. Phys. 79 (1996) 5403-5405.

[7] M.I. Ilyn, A.M. Tishin, K.A. Gschneidner Jr., V.K. Pecharsky, A.O. Pecharsky, Cryocoolers 11, R.G. Ross Jr. (Ed.), Kluwer Academic/Plenum publisher, 2001.

[8] J. Szade, J. Magn. Magn. Mater. 170 (1997) 228-234.

[9] A. Yazdani, M. Molayi, R. Farghadan, J. Magn. Magn. Mater. 310 (2007) e451-e453.

[10] A. Yazdani, B.A. Ravan, J. Magn. Magn. Mater. 321 (2009) 3990-3996.

[11] W.B. Pearson, The Crystal Chemistry and Physics of Metals and Alloys, Wiley, New York, 1972.

[12] C.L. Lin, T. Yuen, T. Mihalisin, Phys. Rev. B 54 (1996) 9254-9258.

[13] Y.B. Kuz'ma, R.V. Skolozdra, Va Markiv, Dopovidi Akademii Nauk Ukrains'koi RSR 1964 (8) (1964) 1070-1072.

[1] W.-L. Liu, M. Yamashita, M. Kurisu, H. Kadomatsu, H. Fujiwara, J. Phys. Soc. Japan 56 (1987) 421-422.

[14] H. Fujiwara, Physica, 119B, (1983) 142-148.

[15] V. Singh, A. Bhattacharyya, S. Majumdar, I. Dasgupta, J. Appl. Phys. 111 (5) (2012) 053709.

[16] W. Borgiel, J. Deniszczyk, Acta Phys. Polinica A 97 (2000) 783-786.

[17] D. Ravot, O. Gorochov, T. Roisnel, G. André, F. Bourée-Vigneron, J.A. Hodges, Int. J. Mod. Phys. B 7 (1993) 818-821.

[18] A. Bhattacharyya, S. Giri, S. Majumdar, J. Magn. Magn. Mater. 324 (2012) 1239-1241. 